\title{
„DOING THE FAMILY". ANALIZA PROBLEMÓW NIEEFEKTYWNYCH STRATEGII AKULTURACYJNYCH, ZWIĄZANYCH Z WZORCAMI SAMOORGANIZACJI RODZINY EMIGRACYJNEJ
}

Wobec zwiększajacej się liczby ruchów ludnościowych zasadne wydaje się podejmowanie badań nad różnorakimi skutkami migracji, zarówno $w$ sensie jednostkowym, jak i społecznym. Celem pracy jest wglad w mechanizmy samoorganizacji polskiej rodziny emigracyjnej, z wykorzystaniem systemowej perspektywy rozumienia rodziny migracyjnej, inspirowana podejściem $S$. Minuchina i takich ram teoretycznych, jak koncepcja ,dzieci trzeciej kultury” $R$. H. Ussem oraz problemów akulturacji, roli sieci społecznego wsparcia a także psychologii miejsca-nie-miejsca M. Augé.

Dzięki zebranym metoda wywiadu zogniskowanego oraz rozmów indywidualnych, jakościowo przeanalizowanym w grupie 48 rodziców (przy uwzględnieniu zmiennych: bliskości międzypokoleniowej, wzorców relacji zewnętrznych oraz unikatowej dla rodziny emigracyjnej zmiennej relacji z miejscem pobytu) informa ejom przyporzadkowano trzy modele funkcjonowania rodziny emigracyjnej, wyjaśniajace problemy nieefektywnych strategii akulturacyjnych na emigracji. Modele te odpowiadaja rodzinom spójnym - uwikłanym - splątanym wg S. Minuchina: „rodzina-magnes” (o dużej bliskości międzypokoleniowej, wysokim poziomie lęku grupowego i spójnych wzorcach kontaktów zewnętrznych, wytwarzajaca w efekcie relatywizm miejsca), ,rodzina-kotwica (o niskiej bliskości międzypokoleniowej, niespójnych wzorcach kontaktów zewnętrznych, wytwarzajaca problem nieumiejscowienia oraz fatamorgane kotwicy u dzieci i separacji u rodziców) oraz

* Wioletta Tuszyńska-Bogucka - dr hab., prof. Wyższej Szkoły Ekonomii i Innowacji w Lublinie, Instytut Psychologii. Zainteresowania naukowe: przemiany rodziny współczesnej, rodzinne uwarunkowania dysfunkcjonalności dziecka, biopsychospołeczny model choroby, życie w świecie mediów. 
„rodzina-repelent” (o niskiej bliskości międzypokoleniowej, niespójnych wzorcach kontaktów zewnętrznych, wytwarzająca alienację u matki i asymilację u córki).

Stowa kluczowe: rodzina emigracyjna, rodzinne strategie akulturacyjne, rodzina trzeciej kultury.

„Mówia ponglishem, chca indyka na Wigilię, do szkót sobotnich chodza niechętnie.

Ale $i$ w Wielkiej Brytanii, Irlandii, Niemczech czy

Hiszpanii też nie czują się jak w domu.

Właśnie dorasta pierwsze masowe pokolenie naszych dzieci trzeciej kultury.

Tylko nie wiadomo, na kogo: Polaków, Brytyjczyków

czy może Europejczyków. (...)”l

\section{Wprowadzenie}

W związku ze specyfiką współczesnego życia, dla którego migracja stała się normalnym, codziennym elementem-żyeia, obszar ten stał się terenem badań, wnikających w przyczyny, a także skutki ruchów ludnościowych w różnorakim kontekście. Piśmiennictwo, dotyczące problemów emigracji, obejmuje głównie problemy statystyczne oraz prawne migracji, skutki rozdzielenia rodzin z powodów emigracji zarobkowej oraz efekty ekonomiczne ruchów ludnościowych. Zaliczyć tu można np. studia Grigoriego i Melkoniana² ${ }^{2}$ którzy stwierdzają, że w Armenii osoby, otrzymujące przekazy pieniężne od bliskich zza granicy zmniejszają aktywność zawodową. Podobnie $\mathrm{Kim}^{3}$ wskazuje, że dochody tak uzyskiwane wpływają negatywnie na rynek pracy na Jamajce. Rodriguez i Tiongson ${ }^{4}$ potwierdzają

\footnotetext{
S. Czubkowska, S. Klinger, Mówia ponglishem, chca indyka na Wigilię. Co dalej z dziećmi Polaków na migracji?, 11.08.2013, http://m.dziennik.pl/wiadomosci/swiat/mowia-ponglishem-chca-indyka-na-wigilie-co-dalej-z-dziecm-polakow-na-migracji [dostęp: 20.02.2014]

2 D. A. Grigorian, T. A. Melkonyan, Destined to receive: The impact of emittances on household decisions in Armenia, ,Review of Development Economics” 2011, nr 15 (1), s. 139-153.

3 N. Kim, The impact of remittances on labor supply: The case of Jamaica, Washington 2007, s. 16.

$4 \quad$ E. R. Rodriguez, E. R. Tiongson, Temporary migration overseas and household labors upply: Evidence from urban Philippines, „International Migration Review” 2001, nr 35(3), s. 709-725.
} 
podobną sytuację na Filipinach, a Funkhouser - w Nikaragui ${ }^{5}$. W Polsce do najbardziej znanych należą prace, dotyczące imigrantów z Wietnamu ${ }^{6}$, czy Chin ${ }^{7}$, ujmowanych jednak raczej $w$ ich etnicznych charakterystykach. Ponadto notuje się dużą liczbę doniesień, dotyczących problemów eurosieroctwa ${ }^{8}$.

Wydaje się, że brakuje jednak badań psychologicznych, dotyczących funkcjonowania i tworzenia się tzw. rodziny emigracyjnej, funkcjonującej poza granicami swojego kraju, a zwłaszcza czynników efektywnej/nieefektywnej adaptacji do nowych warunków życia - ważny tu wydaje się model Georgesa, zakładający, że rodzina jest elementem odpowiedzialnym za relację kontekst - kulturowo specyficzne zmienne psychologiczne ${ }^{9}$. Należą tu prace Pessar ${ }^{10}$, która, badając w Nowym Jorku rodziny przybyłe z Dominikany, dowodzi, iż zmieniły one strukturę - kobiety zaczęły pracować zarobkowo, często zarabiając więcej niż ich mężowie, co zmieniło strukturę siłową rodziny oraz dystrybucję władzy (niestety, zmiana ta często okazała się równocześnie zgubna dla rodziny, niszcząc jej tradycyjną strukturę i wywołując konflikty). Badając migrantów z Meksyku do USA Hondagneu, Sotelo twierdzi, że ludzie nie migrują w wyniku uzgodnionych strategii rodzinnych, ale raczej z powodu konfliktów negocjacji w ramach rodzin i sieci społecznych. Migracja rodzinna wpływa na przekształcanie się indywidualnych stylów życia i zmianę skostniałych relacji rodzinnych, często w kierunku bardziej egalitarnym ${ }^{11}$. Wydaje się więc, że aby przetrwać w niekiedy skrajnie odmiennych warunkach

5 E. Funkhouser, Migration from Nicaragua: Some recent evidence, „World Development" 1992, nr 20(8), s. 1209-1218.

${ }_{6} \quad$ T. Halik, Migrancka społeczność Wietnamczyków w Polsce w świetle polityki państwa i ocen społecznych, Poznań 2006, s. 16-52.

7 Por. np. Sprzedawać, budować, gotować. Plany i strategie Chińczyków i Wietnamczyków w Polsce, red. K. Wysieńska, Warszawa 2012.

8 S. Kozak, Patologia eurosieroctwa w Polsce. Skutki migracji zarobkowej dla dzieci i ich rodzin, Warszawa 2010, s. 113; A. Nowakowska, Wptyw migracji zarobkowej na jakość życia rodzinnego, w: Matżeństwo i rodzina wobec wspótczesnych wyzwań, red. T. Rostowska, Warszawa 2009, s. 101-116; G. Miłkowska, Wychowawcze i społeczne skutki emigracji zarobkowej dla rozwoju dzieci (na przykładzie regionu częstochowskiego), w: Smak emigracji. Dramaty dzieci, red. M. Janukowycz, Kraków 2009, s. 104.

9 J. Georges, S. Christakopoulou, Y. H. Poortinga i in., The relationship of family bonds to family structure and functiona across cultures, red. T. Rostowska, „Journal of Cross-Cultural Psychology" 1997, nr 28, s. 303-320.

10 P. Pessar, A Visa for a Dream: Dominicans in the United States, Boston 1995, s. 98.

1 Za: M. Muszel, Tradycyjna rola w nietradycyjnej rodzinie. Transnarodowa migracja polskich żon i matek - studium przypadku, „InterAlia. A journal of Queer Studies” 2013, nr 8, s. 2. 
funkcjonowaniąrodziny te muszą wdrożyć specyficzne „strategie przetrwania”,12, które nazwać można strategiami akulturacji.

\section{„Rodzina dwóch światów”. Zachowanie kultury i tożsamości czy trening komunikacji międzykulturowej?}

Osoby dorosłe, które zdecydowały się na życie w nowej ojczyźnie, zwykle nie zdają sobie sprawy z konsekwencji psychologicznych takiego kroku. Oprócz nauki nowego języka czy też korzystania z wyuczonego języka obcego, ale używanego w naturalnym środowisku, emigrant stoi przed koniecznością budowania nowej tożsamości kulturowej ${ }^{13}$. Dwukulturowością określa się równorzędne „zanurzenie" w dwóch kulturach - funkcjonowanie i czerpanie z dwóch różnych tradycji, zwyczajów, dorobku kulturowego. Osoba dwujęzyczna, jaką zazwyczaj staje się młody człowiek w rodzinie na emigracji, przejmuje mniej lub bardziej świadomie znaczenia i kody kulturowe, jakie niesie w sobie język nowej ojczyzny. Tym samym może ona żyć w swoistym rozszczepieniu, „zanurzona” w dwóch kulturowych rzeczywistościach. Zakładając, iż język jest swoistym narzędziem funkcjonowania w danej społeczności, ten swoisty dualizm językowy może być przyczyną frustracji i zagubienia oraz problemów z kształtowaniem tożsamości młodego człowieka.

Warto dodać, że w literaturze powstało już pojęcie tzw. „kulturowej bezdomności", która może być negatywnym efektem życiu w wielokulturowości i spowodować wiele problemów natury emocjonalnej i społecznej ${ }^{14}$.

Problemem, z którym zmaga się często rodzina emigracyjna jest także tzw. etniczna wyjątkowość ${ }^{15}$, związana ze specyficznymi zwyczajami, normami, tradycjami i obrzędami, które w nowym świecie mogą być trudne do kultywowa-

12 A. De Haan, Imigration as family strategy: Rural-Urban Labor Migration in India during the Twentieth Century, "The History of The Family” 1997, nr 2(4), s. 481-505; O. Stark, The Migration of Labour, Oxford 1991, s. 56-211; E. Strasser, A. Kraler, S. Bonjour, V. Bilger, Doing family Responses to the constructions of 'the migrant family' across Europe, „History of the Family” 2009, nr 14, s. 165-176.

13 Z. Zaleski, Emigracja i adaptacja - Komu korzyści, a komu straty kulturowe?, w: Migracja - wyzwanie XXI wieku, red. M. S. Zięba, Lublin 2008, s. 118-121.

14 V. N. Vivero, S. R. Jenkins, Existential hazards of the multicultural individual: Defining and understanding ,cultural homelessness”, „Cultural Diversity \& Ethnic Minority Psychology” 1999, nr 5, s. 6-26; R. C. Hoersting, S. R. Jenkins, No place to call home: Cultural homelessness, self-esteem and cross-cultural identities, „International Journal of Intercultural Relations" 2011, nr 35, s. 17-30.

15 F. Anthias, Ethnic ties: Social capital and the question of mobilization, „The Sociological Review” 2007, nr 55(4), s. 788-805. J. Belchem, Irish and Polish migration, 
nia i stanowić właśnie o owej wyjątkowej etniczności. Z drugiej strony bywa to niekiedy wartościowane pozytywnie przez otoczenie, jako okazja do przeżycia nowych, interesujących sytuacji czy zdobycia nowej wiedzy.

Rodziny emigracyjne doświadczają również - poza oczywistym stresem związanym z samą migracją - głębokiego szoku kulturowego, który często prowadzi do konfliktów w rodzinie ${ }^{16}$. Dzieje się tak na skutek zmieniającego się stosunku relacji władzy w rodzinie migrantów ${ }^{17}$. Być może dlatego właśnie często słyszy się o występowaniu wśród emigrantów zaburzeń natury psychicznej, takich jak depresja, zaburzenia nerwicowe czy patologiczne zachowania, jak nadużywanie alkoholu, narkotyków oraz popełnianie przestępstw ${ }^{18}$.

Warto przywołać tu konstrukt rodziny, stającej się ,koalicją przeciw reszcie świata", co prowadzić może nawet do ciężkich zaburzeń - gdy np. negatywna tożsamość grupowa koreluje z większym ryzykiem wystąpienia schizofrenii ${ }^{19}$. Tymczasem umiejętność radzenia sobie z lękiem i stresem akulturacyjnym sprzyja otwartości na kontakt międzykulturowy, inspiruje do nawiązywania coraz to nowych relacji, zachęca do podejmowania nowych wyzwań i ról na płaszczyźnie społecznej, zawodowej i politycznej, prowadząc tym samym ku coraz lepszej integracji z tuziemcami w nowym kraju pobytu ${ }^{20}$.

Do sytuacji dzieci dzisiejszych migrantów najlepiej odnosi się teoria dzieci trzeciej kultury (,Third Culture Child”). Termin ten został stworzony w latach 50. ubiegłego wieku przez amerykańską antropolog R. H. Useem ${ }^{21}$. Początkowo odnosił się głównie do dzieci uchodźców, ambasadorów, urzędników państwowych, przedsiębiorców, wojskowych, misjonarzy. Dzisiaj socjolodzy, psycholodzy i antropolodzy rozszerzają ten termin także na potomstwo nowych emigrantów,

w: Irish and Polish migration in comparative perspective, red. J. Belchem, K. Tenfelde, Essen 2003, s. 11-25.

16 M. Muszel, Tradycyjna rola $w$ nietradycyjnej rodzinie..., dz. cyt., s. 2-3.

17 M. Darvishpour, Immigrant Women Challenge the Role of Men: How the Changing Power Relationship within Iranian Families in Sweden Intensifies Family Conflicts after Migration, ,Journal of Comparative Family Studies” 2002, nr 33 (2), s. 271-296.

18 A. Nowakowska, Wptyw migracji zarobkowej na jakość życia rodzinnego, dz. cyt., s. $101-116$.

19 V. Veling, H. W. Hoek, D. Wiersma, J. P. Mackenbach, Ethnic identity and the risk of schizophrenia in ethnic inorities: A case-control study, „Schizophrenia Bulletin” 2009, nr 36 (6), s. 1149-1156.

20 O. Stark, The Migration of Labour, dz. cyt., s. 480-490; A. De Haan, Imigration as family strategy..., dz. cyt., s. 481-505.

${ }^{21}$ J. Useem, J. D. Donoghue, R. H. Useem, Men in the middle of the third culture, „Human Organization” 1963, nr 22(3), s. 169-179. 
nie tyle uciekających przed biedą czy prześladowaniami, ile szukających lepszej, bardziej stabilnej sytuacji ekonomicznej, szansy awansu i rozwoju ${ }^{22}$.

\section{Rola powiązań w ramach sieci migracyjnych}

Badania nad rolą powiązań w społecznych sieciach migracyjnych powstają już od lat osiemdziesiątych. Układy tego rodzaju definiuje się jako zbiór relacji i więzi społecznych ${ }^{23}$, będących głównymi źródłami doświadczania przyjaźni oraz pomocy $^{24}$. Niestety, w swym skrajnym wymiarze funkcjonowanie w jedynej sieci wsparcia (najczęściej w obrębie własnej grupy etnicznej) doprowadzić może do zjawiska tzw. gettoizacji, niebezpiecznego zarówno dla osób weń tkwiących, jak i dla otoczenia społecznego ${ }^{25}$. Chiswick i Miller $^{26}$ stwierdzają np., że imigranci, zamieszkujący wśród swoich ziomków mają istotnie niższy poziom znajomości nowego języka - w tym wypadku więc sieć wsparcia zadziałała blokująco na jego przyswajanie.

Wydaje się więc, iż sieć wsparcia rozpatrywana być winna w dwóch aspektach wpływu pozytywnego i negatywnego na przebieg procesu adaptacji przybyszów do warunków nowego miejsca pobytu.

\section{Nowa ojczyzna - miejsce czy nie-miejsce?}

Twórcą pojęcia „nie-miejsca” jest światowej sławy francuski etnolog i antropolog kulturowy, wieloletni dyrektor paryskiej École des Hautes Études en Sciences Sociales, M. Augé. Tytułowe nie-miejsca to przestrzenie anonimowe, jak dworce kolejowe, lotniska, stacje metra, supermarkety, pokoje hotelowe czy środki transportu publicznego. I jakkolwiek zapełniają się one codziennie ludźmi,

22 A. M. Moore, G. G. Barker, Confused or multicultural: Third culture individuals' cultural identity, „International Journal of Intercultural Relations” 2012, nr 36, s. 553-162.

23 M. Boyd, Family and personal networks in international migration, „International Migration Review" 1989, nr 23(3), s. 638-670.

24 L. Ryan, R. Sales, M. Tilki, B. Siara, Social networks, social support and social capital: The experiences of recent Polish migrants in London, ,Sociology” 2008, nr 42(4), s. 672-690.

25 A. Gąsior-Niemiec, Europa wobec problemu imigracji, „Polityka i Społeczeństwo” 2007, nr 4, s. 66-75.

26 B. Chiswick, P. Miller, Language in the labor market: The immigrant experience in Canad and the United States, w: Immigration, language and ethnic issues: Canada and the United States, red. B. Chiswick, Washington 1992, s. 229-296. 
to przestrzenie te nie tworzą ani tożsamości, ani relacji, lecz jedynie podobieństwo i samotność. Wydaje się, że położenie człowieka za granicą, nie powiązanego żadnymi więziami z otoczeniem, można porównać do sytuacji przebywania w „nie-miejscu”. Dzieje się tak zwłaszcza u osób, które często przeprowadzały się i w efekcie nie mają wytworzonego przywiązania do konkretnych miejsc. Z kolei „miejsca” to przestrzenie, obdarzone znaczeniem, które oznacza głównie emocjonalny i subiektywny doń stosunek człowieka. Według Twigger-Ross i Uzzell ${ }^{27}$ miejsce jest sposobem na odróżnienie się od innych, aby zachować poczucie ciągłości, budować pozytywną samoocenęa a także wytworzyć poczucie własnej skuteczności. Jak twierdzi Mendel, „miejsca są nie tylko tłem dla życiowego przedstawienia”, ale „nacechowują je zmiany, i odpowiadając na każdą życiową aktywność człowieka, stwarzają go zupełnie tak, jak on tworzy je w wyniku swoich nieustannych ingerencji oraz mniej lub bardziej spektakularnych przekształceń. Można powiedzieć, że miejsca odnoszą się do nas z wzajemnością"28.

Poczucie tożsamości można czuć wobec swojej dzielnicy, miasta, regionu czy kraju, wypada zadać jednak pytanie, czy wytworzenie go jest możliwe, a jeżeli tak, to kiedy, w przypadku emigrantów, a także jakiego rodzaju? (tab. 1).

Tabela 1 . Typy relacji z miejscem ${ }^{29}$

\begin{tabular}{ll}
\hline Typ relacji z miejscem & Opis funkcjonowania \\
\hline \multirow{2}{*}{$\begin{array}{l}\text { Przywiązanie } \\
\text { tradycyjne - separacja }\end{array}$} & $\begin{array}{l}\text { Osoby mało aktywne bądź bierne, o małej mobil- } \\
\text { ności fizycznej (rzadko dokonują zmian w swojej } \\
\text { przestrzeni, rzadko się przeprowadzają, itp.) mocno } \\
\text { hołdujące zwyczajom kraju i kultury pochodzenia, } \\
\text { aktywnie odrzucające nowe zwyczaje i normy. }\end{array}$ \\
& $\begin{array}{l}\text { Osoby dokonujące całkowitego odłączenia się od } \\
\text { swojej grupy (aż do jej odrzucenia) i przystoso- }\end{array}$ \\
Przywiązanie & $\begin{array}{l}\text { wujące się do życia w innej grupie o odmiennej } \\
\text { nadmierne - asymilacja }\end{array}$ \\
& kulturze.
\end{tabular}

27 C. L. Twigger-Ross, D. L. Uzzell, Place and identity processes, „Journal of Environmental Psychology" 1996, nr 16, s. 205-220.

28 M. Mendel, Społeczeństwo i rytuat. Heterotopia bezdomności, Toruń 2007.

29 Opr. własne na podst. M. Lewicka, Psychologia miejsca, Warszawa 2012, s. 362-363; A. M. Moore, G. G. Barker, Confused or multicultural..., dz. cyt., s. 559-561 oraz P. Boski, Kulturowe ramy zachowań spolecznych, Warszawa 2009, s. 54, 525. 


\begin{tabular}{|c|c|}
\hline Typ relacji z miejscem & Opis funkcjonowania \\
\hline $\begin{array}{l}\text { Przywiązanie } \\
\text { aktywne - integracja }\end{array}$ & $\begin{array}{l}\text { Osoby aktywne kulturowo, zainteresowane spra- } \\
\text { wami lokalnymi. Cechuje je dobry kapitał spo- } \\
\text { łeczny - dobre kontakty sąsiedzkie oraz spory krąg } \\
\text { znajomych }\end{array}$ \\
\hline $\begin{array}{l}\text { Przywiązanie } \\
\text { słabe - alienacja/ } \\
\text { marginalizacja }\end{array}$ & $\begin{array}{l}\text { Osoby ze słabym kapitałem społecznym. Słabe rela- } \\
\text { cje sąsiedzkie, mała liczba znajomych i przyjaciół, } \\
\text { niska aktywność społeczna, głównie ze względu na } \\
\text { słabe kompetencje językowe oraz społeczne. }\end{array}$ \\
\hline $\begin{array}{l}\text { Brak przywiązania - } \\
\text { nieumiejscowienie }\end{array}$ & $\begin{array}{l}\text { Osoby nie potrzebujące miejsca dla swojej autode- } \\
\text { finicji. Definiują się nie poprzez miejsce, z którym } \\
\text { są związani, ale przez swoje wykształcenie, zawód, } \\
\text { rodzinę czy zainteresowania (jestem „europejskim } \\
\text { biznesmenem”) }\end{array}$ \\
\hline $\begin{array}{l}\text { Przywiązanie warun- } \\
\text { kowe - relatywizm } \\
\text { miejsca }\end{array}$ & $\begin{array}{l}\text { Osoby, które stać na wytworzenie przywiązania } \\
\text { do danego miejsca, jednak pod warunkiem, że } \\
\text { spełnia/spełni ono określone kryteria. Jest to więc } \\
\text { raczej przywiązanie warunkowe, a postawy takich } \\
\text { osób wobec danego miejsca mają często charakter } \\
\text { ambiwalentny. }\end{array}$ \\
\hline
\end{tabular}

Należy zastanowić się, czy emigracja, często do miejsc nieznanych i nienaznaczonych istniejącą relacją, nie zaowocuje potraktowaniem nowego miejsca na ziemi jako właśnie „nie-miejsca”. Co więcej - nawet gdy owo „nie-miejsce” zaczyna stawać się „miejscem”, wystąpić mogą tu problemy w tempie zmian u różnych osób w rodzinie (wydaje się np. że dzieci znacznie szybciej i efektywniej mogą uruchamiać ten proces), co grozi sytuacją rozłamową.

Kończąc niniejsze rozważania, warto zaznaczyć, iż literatura nie ogranicza się jednak jedynie do wskazania niebezpieczeństw, tkwiących w sytuacji emigracji. Badania wskazują także na pozytywne efekty wzrastania i przebywania w środowisku wielokulturowym, takie jak większa tolerancja rasowa czy religijna ${ }^{30}$,

30 C. D. Smith, World Citizens and 'Rubber-band nationality, w: Strangers at home: Essays on the effects of living overseas and cominghome to a strange land, red. C. D. Smith, Bayside 1996, s. 189-201. 
zdolności adaptacyjne ${ }^{31}$, zwiększone kompetencje komunikacyjne czy otwartość na przyjmowanie nowości (tzw. transformatywność) ${ }^{32}$.

\section{Wzorce funkcjonowania rodzin emigracyjnych. Badania własne nieefektywnych strategii akulturacyjnych rodzin emigracyjnych}

Powyżej przedstawiony został zarys teoretyczny, który posłużyć może do określenia możliwych efektów opisywanych zjawisk w zastosowaniu do rodziny, funkcjonującej jako system. Opisom specyficznych wzorców przyporządkowane zostały autentyczne przypadki opisów polskich rodzin emigracyjnych, z jakimi autorka zetknęła się i pracowała podczas kilku pobytów naukowo-szkoleniowych pod postacią warsztatów umiejętności wychowawczych dla rodziców ${ }^{33}$ (przebywających w USA nie mniej niż 6 lat ${ }^{34}$ ) w USA, w latach 2013-2014. Informacje od rodziców zebrane zostały przy pomocy zogniskowanego wywiadu grupowego (mini FGI) w ujęciu Mertona, Fiske i Kendall przy użyciu techniki konstrukcji, z zachowaniem metodologicznych wymogów badania fokusowego (zbadano 6 grup po 8 osób rodziców), zaś od dzieci - za pomocą rozmów indywidualnych. Dobór metod podyktowany został specyfiką badania, w którym statystyczna reprezentatywność nie była istotna, gdyż celem ich była rekonstrukcja ustalonych społecznie znaczeń oraz wzorów postrzegania, myślenia, oceniania i zachowania się, dotyczących funkcjonowania w rodzinie emigracyjnej ${ }^{35}$.

Wymiary, brane pod uwagę̇ to głównie bliskość międzypokoleniowa i wzorce kontaktów zewnętrznych (będące funkcją granic systemowych), do których dodano rodzaj relacji z miejscem pobytu, ważnej dla rodziny emigracyjnej. Wybór podyktowany został systemową perspektywą rozumienia rodziny migracyjnej, inspirowaną podejściem S. Minuchina, według którego te wymiary mogą zostać potraktowane jako ważne mechanizmy rodzinnej kompetencji (profile na osi: typ

31 Y. Y. Kim, Intercultural personhood: Globalization and a way of being, „International Journal of Intercultural Relations" 2008, nr 32(4), s. 359-368.

32 A. M. Moore, G. G. Barker, Confused or multicultural..., dz. cyt., s. 554.

33 Organizator: Centrala Polskich Szkół Dokształcających w Ameryce, Columbia University of New York oraz MSZ w Polsce, którym dziękuję także za możliwość wykonania prezentowanych badań.

34 Wzorem: A. M. Miller, P. J. Chandler, Acculturation, Resilience, and Depression in Midlife Women From the Former Soviet Union, „Nursing Research” 2002, nr 51(1), s. 26-32.

35 B. Grim, A. H. Harmon, J. C. Gromis, Focused Group Interviews as an Innovative QuantiQualitative Methodology (QQM): Integrating Quantitative Elements into a Qualitative Methodology, ,The Qualitative Report” 2006, nr 3, s. 516-537. 
rodziny spójny - rozłączny - splątany) w tworzeniu strategii przetrwania w sytuacjach trudnych ${ }^{36}$ możliwych do opisu za pomocą informacji, uzyskanych przy użyciu metody badań fokusowych.

\section{Zestawienie informacji, dotyczących przykładowych wzorów samoorganizacji}

\section{OPIS PRZYPADKU I.}

Rodzina X, bardzo dobrze funkcjonujaca pod względem materialnym. Mąż posiada dobrze prosperujaca wtasna firmę (ustugi transportowe), zatrudniajaca kilkanaście osób, dobrze włada językiem kraju pobytu. Żona nie pracuje, jednak z wyboru, gdyż nie określa siebie jako „osoby poszukujacej pracy” i sygnalizuje satysfakcję z warunków ekonomicznych osiagniętych przez rodzinę. Dorosty syn, pracujacy w firmie ojca, właśnie został ojcem swojego pierwszego dziecka. Rodzina bardzo starannie kultywująca polskie tradycje świateczne, często odwiedzająca Polskę, ale także spędzająca czas urlopów w innych krajach.

Jak sami określaja, językiem angielskim wtadaja , średnio”.

Na pytanie, z kim ożenit się syn, matka odpowiada: „Oczywiście, że z Polka, a z kimże innym? Polki najlepsze i najtadniejsze".

Na pytanie, czy podoba jej się kraj pobytu odpowiada, że nie, że woli Polskę, równocześnie narzekając na warunki socjalne w niej obecnie panujace-,,ale nie da się tam przecież zyć”. Z drugiej strony - rodzina (głównie matka) jest krytycznie nastawiona do obyczajów kraju pobytu i dość ironicznie je komentująca (,,wszędzie petno tych matych Chińczyków"). Negatywnie ocenia także pomyst społeczeństwa wielokulturowego, jako miejsca niebezpiecznego i ,dziwacznego".

Rodzina zakupów dokonuje głównie w polskich sklepach, stosunki towarzyskie (za wyjątkiem pracującego w różnych środowiskach męża) utrzymuje głównie w obrębie środowisk polonijnych.

Syn bardzo chętnie przebywa w rodzinie, jego młoda żona bardzo ceni sobie pomoc i towarzystwo teściowej, mówiąc: „, My to mamy szczęście, taka pomoc to tylko w polskich rodzinach można spotkać, oni (o nacji kraju pobytu) sa nieczuli

36 M. D. Kretchmar, D. B. Jacobvitz, Observing mother-child relationships across generations: Boundary patterns, attachment, and the transmission of care-giving, „Family Process" 2002, nr 41, s. 351-374; S. Minuchin, Families and family therapy. Cambridge 1974, s. 9-13; J. Stevenson-Hinde, Attachment within family systems: An overview, „Infant Mental Health Journal", 1990, nr 11, s. 18-227. 
na potrzeby młodych, raczej wola podróżować albo spetniać swoje zachcianki, niż zajmować się wnukami”.

Na pytanie, czy chcieliby wrócić do Polski, odpowiadaja: „,Byłoby dobrze, ale gdybyśmy mogli wrócić wszyscy, no i żyć na takim poziomie, jak żyjemy tu".

Opis mechanizmu przypadku I.

Opisywana rodzina wytworzyła wewnętrzny mechanizm magnesu, utrzymujący członków rodziny w dużej bliskości międzypokoleniowej. Przeciwstawiła także panujące w kraju pobytu wzorce dość luźnych kontaktów międzypokoleniowych polskiej tradycji pomocy i struktury, typowej dla rodziny wielopokoleniowej. Wytworzono spójne wzorce kontaktów zewnętrznych, obejmujących różnorodne etnicznie kontakty towarzyskie i zawodowe, co nie odnosi się jednak do kontaktów najbliższych, czyli poszukiwania partnera życiowego.

W efekcie rodzina działa jak magnes na swoich członków, powodując prawdopodobnie proces silnej transmisji wzorców organizacji rodzinnej. W rodzinie występuje zjawisko relatywizmu miejsca oraz nieefektywna strategia akulturacyjna (separacja).

\section{Klasyfikacja wzorca (strategii przetrwania)}

Typ spójny

(cohesive family).

Rodzina jako magnes

\section{OPIS PRZYPADKU II.}

Rodzina Y, gdzie mąż nie pracuje (zasilek chorobowy), żona Rarabia sprzataniem. Dzieci9-letni syn, urodzony już w kraju nowego pobytu, oraz starsze: 17-letni syn oraz 21-letnia córka - urodzeni w Polsce, kontynuujacy (z powodzeniem) naukę w kraju nowego pobytu.

Rodziców cechuje słaba znajomość języka angielskiego.

Mąż przebywający głównie $w$ domu, niechętnie nastawiony do konieczności strukturalizowania na nowo własnej aktywności zawodowej (przekwalifikowania się i szukania nowej pracy), żyjący wspomnieniami „dobrych dawnych czasów” (,wtedy zarabiatem naprawdę dobre pieniadze i stać nas byto praktycznie na 
wszystko"), wykazujacy dość wyraźnie nastawienie prokrastynacyjne wobec rysującej się coraz wyraźniej konieczności przekwalifikowania się i zdobycia nowych możliwości zarobkowania.

Rodzina obchodzi święta i inne rodzinne uroczystości, jednak po „części obowiąkowej" starsze dzieci najchętniej wymykaja się, aby świętować ze swoimi przyjaciótmi na sposób amerykański.

Rodzice dość rzadko wychodza z domu i kontaktują się z osobami pochodzenia nie-polskiego.

Dorosłe dzieci komunikuja się między soba po angielsku, czemu sprzeciwiaja się rodzice, domagajacy się, aby w ,domu mówić po polsku” $i$ w życie rodziny , nie wprowadzać zagranicznych obyczajów” oraz ,tych obcych ludzi”. Stale przekonuja dzieci, aby uczyty się polskiego, używając argumentu, że „wykształcenie, jakie moga zdobyć w Polsce, jest tańsze, a równie dobre jak tutaj”, do czego dzieci odnosza się ambiwalentnie.

Do zeszłego roku ,obowiazkiem” wakacyjnym byt co najmniej trzytygodniowy wyjazd do Polski, gdzie, jak mówi ojciec - ,dzieci miaty okazję poznawać ojczysty kraj, dziadków i prawdziwe życie”. Obecnie najstarsze dzieci sprzeciwity się tej idei, dlatego rodzina zrezygnowała z wyjazdów, gdyż ,jest bez sensu jeździć oddzielnie, no i za drogo, jak nie jedziemy wszyscy, bo trzeba by płacić za wakacje dzieci tu i tu".

Najmłodszy chłopiec postuguje się słabo językiem polskim, jednak pytany, gdzie chciałaby mieszkać, odpowiada (po namyśle): „,w Polsce, bo mama i tata też by chcieli tam wrócić”. Starsze rodzeństwo, pytane, gdzie chciałoby zamieszkać, jest wyraźnie zaktopotane, w obecności rodziców odpowiada twierdzaco, jednak bez nich wypowiada się nieco szerzej, mówiąc, że być może wyjechaliby nawet do innego kraju, niekoniecznie Polski, która ,zaczęła ich już trochę nudzić - ciagle to samo i to samo”, ale „nie wiedza gdzie”. 
Opis mechanizmu przypadku II.

Klasyfikacja wzorca (strategii przetrwania)

Niska bliskość międzypokoleniowa - w opisywanej rodzinie drogi dzieci najprawdopodobniej „rozeszły się” z drogami rodziców. Mają one już inne plany, inne wyobrażenie dotyczące spędzania czasu wolnego, wyboru wykształcenia oraz kariery zawodowej, czego rodzice zdają się nie tylko nie akceptować, ale nawet nie zauważać. Niespójne (rozbieżne) wzorce kontaktów zewnętrznych, nielicznych w przypadku rodziców, którzy dodatkowo nie akceptują kontaktów społecznych dzieci, jakie nawiązały one w środowisku rówieśniczym.

Typ rozłączny (disengaged family).

Rodzina jako kotwica. W efekcie dzieci mogą wytworzyć fatamorganę kotwicy.

Dzieci wykazują tu także problem nieumiejscowienia, zaś rodzice - przywiązanie tradycyjne do Polski. Wystąpiła nieefektywna strategia akulturacyjna, odmienna dla dzieci i rodziców (rodzice - separacja, dzieci - nieumiejscowienie).

\section{OPIS PRZYPADKU III.}

Rodzina Z, matka, po rozwodzie (przyczyna - alkoholizm męża oraz przemoc domowa) samotnie wychowujaca dorastająca, 17-letnia córkę. Matka zarabia na życie sprzataniem, ma niewielkie alimenty oraz korzysta z pomocy socjalnej. Jej znajomość języka angielskiego jest bardzo słaba.

Córka, jak twierdzi, sprawia jej ,nieustanne problemy”, konfliktuje się z innymi dziewczętami w szkole, jest ,niegrzeczna dla nauczycieli”, juz dwa razy uciekła $z$ domu, gdyż, jak mówi matka, „bo jej nie pozwalam na różne głupoty”. Jak sygnalizuje matka, jest po inicjacji narkotykowej: „,Juz brała i wiem o tym”.

Matka, podejmujac próby pomocy, przychodzi po córke pod szkołę, aby zapobiec jej ucieczkom, na co córka reaguje złościa, krzykami ,you're makin' me trouble!” (robisz mi problemy), ,nic nie rozumiesz”, ,po co tu przychodzisz?!”, „,idź do swoich Polaków!", ,ja muszę mieć sleepover ${ }^{37 ”, ~ i t d ., ~ a ~ n a w e t ~ p r o ́ b a m i ~}$ agresji fizycznej wobec matki.

37 „Sleep over" - bardzo popularny w USA zwyczaj młodzieży nocowania u kogoś przy okazji wizyty u niego, odwiedzin, imprezy, itp., tzw. ,piżama-party”). 
Córka, jak mówi matka, nieustannie formutuje pretensje, że ma problemy, gdyż jest Polka, pochodzi z biednej, emigranckiej rodziny i dlatego spotykaja ja przykrości w kontaktach z rówieśnikami, owocujace jej buntem, zachowaniami ryzykownymi i ucieczkami.

Rodzina $w$ zasadzie nie obchodzi świąt ani innych uroczystości rodzinnych, gdyż, jak mówi matka, ,nie ma dla kogo się starać”, no i „lepiej zaoszczędzić pieniadze na ważniejsze wydatki”.

Na pytanie, czy chciałaby wrócić do Polski, córka protestuje gwattownie, matka, wzdychajac odpowiada: „A jak, przecież Pani widzi?”.

Na pytanie, czy korzysta z ustug specjalistów, zajmujacych się pomoca psychologiczno-pedagogiczna, odpowiada, że jej na to nie stać, nie bardzo umie o nia poprosić, a córka i tak pewnie by nie chciała z niej skorzystać, nawet gdyby znalazty się na to pieniadze.

\section{Opis mechanizmu przypadku III.}

Rodzina o skrajnie niskim poziomie bliskości. Całkowicie rozbieżne wzorce kontaktów zewnętrznych. W opisywanej diadzie zaszły także wyraźne zjawiska marginalizacji oraz wykluczenia społecznego - matka w zasadzie wyłączona z jakiejkolwiek sieci wsparcia, córka uciekająca w kontakty nierozumiane i nieakceptowane przez matkę (stąd prawdopodobnie ucieczki z domu).

Problemowa córka nie korzysta z pomocy psychologicznej głównie z przyczyn ekonomicznych a także (prawdopodobnie) barier komunikacyjnych (własnych oraz matki), i doznaje odrzucenia w swojej grupie rówieśniczej, które przypisuje nie tyle swoim problemom, ile pochodzeniu.

Obydwie kobiety wykazują równocześnie problem alienacji oraz nieefektywną strategię akulturacyjną (matka-alienację, powodującą marginalizację, córka - negatywną asymilację).
Klasyfikacja wzorca (strategii przetrwania)
Typ splątany (enmeshed family). Rodzina jako repelent. 


\section{Wnioski i dyskusja}

Jakościowa analiza zebranego materiału badawczego pozwoliła na wyodrębnienie w oparciu o systemowe wymiary funkcjonowania rodziny trzech reprezentatywnych typów samoorganizacji rodziny emigracyjnej (strategii przetrwania), które mogą mieć negatywny wpływ na proces jej adaptacji do nowego środowiska.

$$
\text { Rodzina - „magnes” }
$$

Wydaje się, że problemem, kształtującym wzorce rodziny migracyjnej, a wyraźnie obecnym w rodzinie $\mathrm{X}$ może być stres akulturacyjny, przeżywany najczęściej przez pierwsze pokolenie migrantów. Ma on także znaczenie w kontaktach społecznych - kontaktom międzygrupowym często towarzyszy także lęk grupowy ${ }^{38}$. Wzajemne indukowanie się lękiem we własnej grupie kulturowej to mechanizm, pogłębiający stan niepokoju jednostek, prowadzący do unikania kontaktów z obcymi (tu: nie będącymi członkami Polonii). Umacnia on dystans i wrogość, obniżając możliwości integracyjne jednostek i grup z innymi kulturami ${ }^{39}$. Społeczeństwo amerykańskie posiada wieloetniczny, wielowyznaniowy, wielorasowy charakter, a więc lęk przed innymi kulturami przeszkadzać może w wytworzeniu aktywnego przywiązania do miejsca pobytu i wytworzenie tzw. relatywizmu miejsca a więc rodzaju przywiązania warunkowego, gdy jednostka może wytworzyć więzi z miejscem, jednak pod warunkiem, że spełniać ono będzie określone kryteria (tu - dotyczące materialnych warunków życia). Rodzina w takim wypadku jest środowiskiem silnie oddziałującym na funkcjonujące w jej obrębie jednostki, pełniąc role zabezpieczające i kompensujące, zapewniając bardzo wysoką bliskość oraz spójność wzorców kontaktów zewnętrznych (rodzice i dzieci obracają się podobnym środowisku). Może ona jednak przekształcić się w „bezludną wyspę”, zwłaszcza przy wysokim nasileniu stresu akulturacyjnego i separację (nasilanie się asymilacji negatywnej).

38 M. Wallas, Lęk akulturacyjny cudzoziemców w aspekcie tożsamości i procesów integracyjnych w nowym kraju pobytu, „Środkowoeuropejskie Studia Polityczne” 2010, t. 4, s. 85-86.

39 M. Wallas, Dialog międzykulturowy - szanse i ograniczenia, w: Drogi i bezdroża komunikacji, red. P. Bering, G. Łukomski, Gniezno 2008, s. 260-261. 


\section{Rodzina - „kotwica”, czyli problem „dzieci trzeciej kultury”}

Wczesna literatura lat 30. XX stulecia charakteryzowała „kulturowe hybrydy” jako osoby dysfunkcyjne, bo wyobcowane poprzez odcięcie od korzeni, jednak literatura nowsza (począwszy od Adlera, bo „dziecko trzeciej kultury” odnieść można także do adlerowskiego konstruktu człowieka wielokulturowego, który żyjąc na specyficznym terytorium pomiędzy kulturami, buduje tożsamość opartą zarówno na swojej indywidualności, jak i na wielości doświadczeń kulturowych) zauważa ich potencjały, np. wspominaną już większą tolerancję religijną i rasową czy podwyższoną zdolność do adaptacji. Można tu jednak także przywołać badania Greenholtz i Kim${ }^{40}$, którzy stwierdzają, że owa „kulturowa hybryda” wydaje się czuć doskonale w każdym środowisku kulturowym, podczas gdy w rzeczywistości czuje się jak w domu jedynie wśród podobnych sobie z punktu widzenia historii kultury. Hybrydy te, nazywane w literaturze „dziećmi trzeciej kultury”, często cierpią na fatamorganę kotwicy - zjawisko polegające na poczuciu straty, konieczności powrotu do jakiegoś miejsca, dążeniu do wyjazdu do innego kraju, nawet jeśli pojawia się szansa zamieszkania na stałe tam, gdzie akurat są, często indukowanego przez starsze pokolenie. W swoich krajach pobytu dzieci trzeciej kultury najczęściej mają problemy z wytworzeniem poczucia przynależności i bycia mentalną częścią narodu. Zjawisko to nasila się, gdy w rodzinie występują opisywane powyżej problemy - traktowanie nowego kraju jako „nie-miejsca”, lęk akulturacyjny, nadmierna lojalność wobec przeszłości czy nadmiernego uwikłania w sieci etnicznych powiązań wsparciowych. Mogą one być dobrze dostosowane (głównie dzięki przezwyciężeniu problemów z komunikacją językową), mając poczucie nieadekwatności miejsca, w którym przebywają. Oznacza to, że dzieci trzeciej kultury mogą przechowywać niemal przez całe życie swój jeden, podstawowy problem - czują, że gdzieś przynależą, ale jest to zwykle gdzie indziej, niż w miejscu, w którym właśnie się znajdują.

W rodzinie $Y$ drogi dzieci prawdopodobnie ,rozeszły się” $z$ drogami rodziców, co nazwać można zjawiskiem niespójności wzorów kontaktów zewnętrznych a także - sygnałem obniżenia się poziomu bliskości rodzinnej. Dzieci mają już inne plany, inne wyobrażenie dotyczące spędzania czasu wolnego, wyboru wykształcenia oraz kariery zawodowej, czego rodzice zdają się nie akceptować. W efekcie dzieci mogą wytworzyć fatamorganę kotwicy - miejsca, do którego trzeba dążyć, gdy się je jednak osiąga, nie przynosi to szczęścia, ulgi ani ukojenia,

40 J. Greenholtz, J. Kim, The cultural hybridity of Lena: A multi-method case study of a third culture kid, „International Journal of Intercultural Relations” 2009, nr 33, s. 391-398. 
mało tego - może przynieść poważne zaburzenia funkcjonowania, niejednokrotnie potwierdzane badaniami ${ }^{41}$.

Rodzina - kotwica, gdzie rodzice wykazują separację, tu mógł zaowocować wytworzeniem u dzieci zjawiska nieumiejscowienia, czyniąc z nich jednostki, które do swojej autodefinicji nie potrzebują miejsca, w tym celu używając raczej takich wartości, jak zawód czy zainteresowania. Sprzyja to ich mobilności fizycznej, z drugiej jednak strony wpływa negatywnie na procesy wytwarzania więzi.

$$
\text { Rodzina - „repelent” (środek odstraszający) }
$$

W literaturze wymieniane są potencjalne problemy, wynikające $\mathrm{z}$ faktu pochodzenia i życia w rodzinie migracyjnej:

- zakłócenia w podstawowych obszarach życia migranta i członków jego rodziny: pracy, konsumpcji, edukacji, zdrowiu, kulturze;

- zmiana pozycji społecznej jednostki i/lub rodziny (degradacja) w kraju przyjmującym w porównaniu z krajem pochodzenia;

- zjawiska marginalizacji i wykluczenia;

- brak uczestnictwa, wycofanie, ograniczenie realizacji ról społecznych (w sytuacji, gdy istnieje oczekiwanie, że podjęte zostaną, zgodne z wiekiem, sytuacją życiową, konkretne role np. ojca, matki);

- brak korzystania ze świadczeń i uczestnictwa w podstawowych instytucjach życia społecznego (np. ograniczenia w korzystaniu z edukacji, opieki zdrowotnej, świadczeń socjalnych, emerytalnych, odliczeń podatku, brak lub ograniczenie dostępu do praktyk religijnych, brak uczestnictwa w wyborach i w kraju pochodzenia, który się opuściło i w kraju przyjmującym, w którym nie uzyskano prawa wyborczego itp. $)^{42}$.

${ }^{41}$ C. Corcoran, M. Perrin, S. Harlap i in., Incidence of schizophrenia among second-generation immigrants in the Jerusalem perinatal cohort, „Schizophrenia Bulletin” 2008, nr 35(30), s. 596-602.

42 Z. Kawczyńska-Butrym, Migracja: Perspektywa mikrospołeczna-indywidualne i rodzinne zyski, koszty i straty, w: Migracja - wyzwanie XXI wieku, red. M. S. Zięba, Lublin 2008, s. 27; J. Surzykiewicz, Współczesne dziewczyny nie maja problemów? Obraz współczesnych nastolatek i jego znaczenie $w$ pracy edukacyjno-wychowawczej z dziewczętami, Warszawa 2012, s. 3-4. 
Potwierdzają to np. badania Clement, Noels, Deneault ${ }^{43}$, wykazujące, że poziom dyskryminacji (i związane z tym negatywne zjawiska społeczne, psychologiczne i ekonomiczne) jest wyższy wobec środowisk, tworzących enklawy etniczne.

Opisywana rodzina, oprócz wielu problemów, typowych dla słabo komunikujących się i niekorzystających z dóbr kultury, a także - przeżywających poważny problem w postaci braku więzi (spójności) i całkowicie niespójnych wzorców kontaktów zewnętrznych (nierozumianych i wręcz nienawidzonych wzajemnie przez strony rodzinnego konfliktu, a więc matkę i córkę)_zasygnalizowała jeszcze dodatkowy problem alienacji u matki, wynikający prawdopodobnie ze słabych relacji społecznych oraz niskiej społecznej aktywności oraz nadmiernej asymilacji u córki. Zjawiska te wywierają niewątpliwie doniosły wpływ na słabość procesu adaptacji kulturowej i społecznej rodziny, w postaci marginalizacji.

Typ, jaki utworzyła rodzina, wyraźnie może pogarszać sytuację córki, która boleśnie odczuwa swą marginalizację i wykluczenie ze środowiska, ewidentnie wiążąc je ze swym pochodzeniem. Należy nadmienić, iż wspominany „repelent” rodzinny działa także na dorastającą córkę, która wyraźnie ucieka od modelu, zaproponowanego przez matkę, wiążąc go z pochodzeniem i próbując za wszelką cenę upodobnić się do amerykańskich rówieśników, choćby za cenę podjęcia zachowań ryzykownych (np. inicjacji narkotykowej).

Żadna z opisywanych rodzin nie przyjęła jedynej w zasadzie efektywnej strategii akulturacyjnej, a więc integracji (przyjęcie obcej kultury z zachowaniem własnej). Wybrały one raczej separację, alienację lub relatywizm miejsca, co zabezpiecza je przed zewnętrznymi wpływami (raczej jednak we własnym odczuciu), gdyż stanowi strategie błędne lub przynajmniej nieefektywne ${ }^{44}$ i prowadzić może do pustki, zwłaszcza u dzieci, w której pojawić się mogą zjawiska nieumiejscowienia lub wręcz zjawiska groźne, jak np. inicjacja narkotykowa czy ucieczki z domu.

Podsumowując opisane powyżej problemy psychologiczne, powiązane z migracją rodzinną, można powiedzieć, że sposób stawania się rodziną migracyjną stanowi istotny czynnik określający charakter i szanse procesu integracji. Wydaje się, że obszar ten wart jest podjęcia działań eksploracyjnych, zarówno ze względu na powinność moralną pomocy, jaką winniśmy rodakom, nawet, gdy wybrali

43 R. Clement, K. A. Noels, B. Deneault, Interethnic Contact, Identity, and Psychological Adjustment: The Mediating and Moderating Roles of Communication, „Journal of Social Issues" 2001, nr 53 (3), s. 559-577.

44 M. Szopski, Komunikowanie międzykulturowe, Warszawa 2005, s. 5; M. Navas, A. J. Rojasb, M. Garcíac, P. Pumaresd, Acculturation strategies and attitudes according to the Relative Acculturation Extended Model (RAEM): The perspectives of natives versus immigrants, „International Journal of Intercultural Relations” 2007, nr 31(1), s. 67-86. 
życie w oddali, jak i ze względu, że przybywający z kolei do nas imigranci (co ze względu na europejską implozję demograficzną wydaje się być zjawiskiem korzystnym) mogą mieć analogiczne problemy, których poznanie pomoże nam wdrożyć procedury ułatwiające ich adaptację, a im odnaleźć się w naszym świecie.

\section{Literatura}

Anthias F., Ethnic ties: Social capital and the question of mobilization, „The Sociological Review" 2007, nr 55(4), s. 788-805.

Belchem J., Irish and Polish migration, w: Irish and Polish migration in comparative perspective, red. J. Belchem, K. Tenfelde, Essen 2003, s. 11-25.

Boski P., Kulturowe ramy zachowań społecznych, Warszawa 2009.

Boyd M., Family and personal networks in international migration, „International Migration Review" 1989, nr 23(3), s. 638-670.

Chiswick B., Miller P., Language in the labor market: The immigrant experience in Canada and the United States, w: Immigration, language and ethnic issues: Canada and the United States, red. B. Chiswick, Washington 1992, s. 229-296.

Clement R., K. Noels A., Deneault B., Interethnic Contact, Identity, and Psychological Adjustment: The Mediating and Moderating Roles of Communication, ,Journal of Social Issues" 2001, nr 53 (3), s. 559-577.

Corcoran C., Perrin M., Harlap S. i in., Incidence of schizophrenia among second-generation immigrants in the Jerusalem perinatal cohort, „Schizophrenia Bulletin" 2008, nr 35(30), s. 596-602.

Czubkowska S., Klinger S., Mówia ponglishem, chca indyka na Wigilię. Co dalej z dziećmi Polaków na migracji?, 11.08.2013, http://m.dziennik.pl/wiadomosci/ swiat/mowia-ponglishem-chca-indyka-na-wigilie-co-dalej-z-dziecm-polakow-na-migracji [dostęp: 20.02.2014]

Darvishpour M., Immigrant Women Challenge the Role of Men: How the Changing Power Relationship within Iranian Families in Sweden Intensifies Family Conflicts after Migration, „Journal of Comparative Family Studies” 2002, nr 33 (2), s. 271-296.

De Haan A., Imigration as family strategy: Rural-Urban Labor Migration in India during the Twentieth Century, „The History of The Family” 1997, nr 2(4), s. 481-505.

Funkhouser E., Migration from Nicaragua: Some recent evidence, „World Development" 1992, nr 20(8), s. 1209-1218.

Gąsior-Niemiec A., Europa wobec problemu imigracji, „Polityka i Społeczeństwo” 2007, nr 4, s. 66-75. 
Georges J., Christakopoulou S., Poortinga Y. H. i in., The relationship of family bonds to family structure and functiona across cultures, red. T. Rostowska, Journal of Cross-Cultural Psychology" 1997, nr 28, s. 303-320.

Greenholtz J., Kim J., The cultural hybridity of Lena: A multi-method case study of a third culture kid, „International Journal of Intercultural Relations” 2009, nr 33, s. 391-398.

Grigorian D. A., Melkonyan T. A., Destined to receive: The impact of emittances on household decisions in Armenia, "Review of Development Economics” 2011, nr 15 (1), s. 139-153.

Grim B., Harmon A. H., Gromis J. C., Focused Group Interviews as an Innovative QuantiQualitative Methodology (QQM ): Integrating Quantitative Elements into a Qualitative Methodology, „The Qualitative Report”2006, nr 3, s. 516-537.

Halik T., Migrancka społeczność Wietnamczyków w Polsce w świetle polityki państwa i ocen społecznych, Poznań 2006.

Hoersting R. C., Jenkins S. R., No place to call home: Cultural homelessness, self-esteem and cross-cultural identities, „International Journal of Intercultural Relations" 2011, nr 35, s. 17-30.

Kawczyńska-Butrym Z., Migracja: Perspektywa mikrospołeczna-indywidualne $i$ rodzinne zyski, koszty i straty, w: Migracja - wyzwanie XXI wieku, red. M. S. Zięba, Lublin 2008, s. 27.

Kim N., The impact of remittances on labor supply: The case of Jamaica, Washington 2007.

Kim Y. Y., Intercultural personhood: Globalization and a way of being, „International Journal of Intercultural Relations” 2008, nr 32(4), s. 359-368.

Kozak S., Patologia eurosieroctwa w Polsce. Skutki migracji zarobkowej dla dzieci i ich rodzin, Warszawa 2010.

Kretchmar M. D., Jacobvitz D. B., Observing mother-child relationships across generations: Boundary patterns, attachment, and the transmission of care-giving, „Family Process” 2002, nr 41, s. 351-374.

Lewicka M., Psychologia miejsca, Warszawa 2012.

Mendel M., Społeczeństwo i rytuał. Heterotopia bezdomności, Toruń 2007.

Miller A. M., Chandler P. J., Acculturation, Resilience, and Depression in Midlife Women From the Former Soviet Union, „Nursing Research” 2002, nr 51(1), s. 26-32.

Miłkowska G., Wychowawcze i społeczne skutki emigracji zarobkowej dla rozwoju dzieci (na przykładzie regionu częstochowskiego), w: Smak emigracji. Dramaty dzieci, red. M. Janukowycz, Kraków 2009, s. 104.

Minuchin S., Families and family therapy. Cambridge 1974, s. 9-13. 
Moore A. M., Barker G. G., Confused or multicultural: Third culture individuals' cultural identity, ,International Journal of Intercultural Relations” 2012, nr 36, s. 553-162.

Muszel M., Tradycyjna rola w nietradycyjnej rodzinie. Transnarodowa migracja polskich żon i matek - studium przypadku, „InterAlia. A journal of Queer Studies" 2013, nr 8, s. 2.

Navas M., Rojasb A. J., Garcíac M., Pumaresd P., Acculturation strategies and attitudes according to the Relative Acculturation Extended Model (RAEM): The perspectives of natives versus immigrants, „International Journal of Intercultural Relations" 2007, nr 31(1), s. 67-86.

Nowakowska A., Wpływ migracji zarobkowej na jakość życia rodzinnego, w: Matżeństwo i rodzina wobec współczesnych wyzwań, red. T. Rostowska, Warszawa 2009, s. 101-116.

Pessar P., A Visa for a Dream: Dominicans in the United States, Boston 1995.

Rodriguez E. R., Tiongson E. R., Temporary migration overseas and household labors upply: Evidence from urban Philippines, „International Migration Review” 2001, nr 35(3), s. 709-725.

Ryan L., Sales R., Tilki M., Siara B., Social networks, social support and social capital: The experiences of recent Polish migrants in London, „Sociology” 2008, nr 42(4), s. 672-690.

Smith C. D., World Citizens and 'Rubber-band nationality, w: Strangers at home: Essays on the effects of living overseas and cominghome to a strange land, red. C. D. Smith, Bayside 1996, s. 189-201.

Sprzedawać, budować, gotować. Plany i strategie Chińczyków i Wietnamczyków w Polsce, red. K. Wysieńska, Warszawa 2012.

Stark O., The Migration of Labour, Oxford 1991.

Stevenson-Hinde J., Attachment within family systems: An overview, „Infant Mental Health Journal", 1990, nr 11, s. 18-227.

Strasser E., Kraler A., Bonjour S., Bilger V., Doing family Responses to the constructions of 'the migrant family' across Europe, „History of the Family” 2009, nr 14, s. 165-176.

Surzykiewicz J., Współczesne dziewczyny nie maja problemów? Obraz współczesnych nastolatek i jego znaczenie w pracy edukacyjno-wychowawczej z dziewczętami, Warszawa 2012.

Szopski M., Komunikowanie międzykulturowe, Warszawa 2005.

Twigger-Ross C. L., Uzzell D. L., Place and identity processes, „Journal of Environmental Psychology" 1996, nr 16, s. 205-220.

Useem J., Donoghue J. D., Useem R. H., Men in the middle of the third culture, „Human Organization” 1963, nr 22(3), s. 169-179. 
Veling V., H. Hoek W., Wiersma D., Mackenbach J. P., Ethnic identity and the risk of schizophrenia in ethnic inorities: A case-control study, „Schizophrenia Bulletin" 2009, nr 36 (6), s. 1149-1156.

Vivero V. N., Jenkins S. R., Existential hazards of the multicultural individual: Defining and understanding ,cultural homelessness”, „Cultural Diversity \& Ethnic Minority Psychology" 1999, nr 5, s. 6-26.

Wallas M., Dialog międzykulturowy - szanse i ograniczenia, w: Drogi i bezdroża komunikacji, red. P. Bering, G. Łukomski, Gniezno 2008, s. 260-261.

Wallas M., Lęk akulturacyjny cudzoziemców w aspekcie tożsamości i procesów integracyjnych w nowym kraju pobytu, „Środkowoeuropejskie Studia Polityczne” 2010, t. 4, s. 85-86.

Zaleski Z., Emigracja i adaptacja - Komu korzyści, a komu straty kulturowe?, w: Migracja - wyzwanie XXI wieku, red. M. S. Zięba, Lublin 2008, s. 118-121.

\section{Wioletta Tuszyńska-Bogucka: Problems of inefficient acculturation strategies, related to emigrational family self-organization patterns}

The aim of this paper is to provide an insight into the specificity of emigrational family functioning as a important factor for its positive adaptation in the new culture. The Theory of "Third Culture Kid" by R.H. Useem and acculturation related problems, the role of social support net and psychology of "Place-No place" by M. Augé are introduced as a possible explanation of ways of self-organizing Polish emigrational families at USA, with using the terms of family organization by S. Minuchin: cohesive-disengaged-enmeshed family systems.

Information, collected by FGI method and analyzed by qualitative methods (48 Polish parents, living at the USA) show that three types of families can be responsible for some ineffective acculturation strategies: "family- magnet" (high level of family cohesion, high level of group anxiety and consistent patterns of external relations, causing place's relativism), "family-anchor" (low level of cohesion, inconsistent patterns of external relations, causing the problems of no location and mirage anchor at children and assimilation at parents) and "family-repellent" (low level of cohesion, inconsistent patterns of external relations, making problem of alienation in mother and negative assimilation in daughter).

Key-words: emigrational family, family acculturation strategies, third culture family. 